\title{
Penerapan Kerangka Cobit 4.1 dalam Audit Pengaruh POS terhadap OCB Dosen STMIK STIKOM Bali
}

\author{
Paula Dewanti \\ Program Studi Sistem Komputer, STMIK STIKOM Bali \\ J1. Raya Puputan No.86, Renon - Denpasar, 0361-244446 \\ e-mail: pdewanti @gmail.com
}

\begin{abstract}
Abstrak
Perkembangan dunia usaha yang melibatkan Teknologi Informasi (TI), menyebabkan meningkatnya permintaan terhadap tenaga kerja TI. Hal ini diikuti dengan kemunculan kampus-kampus TI baru yang menyebabkan persaingan antar kampus berlangsung semakin kompetitif dikarenakan adanya tuntutan akan lulusan yang berkualitas, agar mampu bersaing dan memberikan kontribusi berupa hasil kerja yang maksimal sesuai yang diharapkan oleh pasar. Hal ini tidak terlepas dari ketersediaan Dosen yang memenuhi standar dan kualifikasi. Penelitian ini menggunakan STMIK STIKOM Bali sebagai contoh studi kasus. Sebagai salah satu perguruan tinggi swasta di peringkat 3 nasional dan peringkat 1 Bali Nusra, diharapkan STMIK STIKOM Bali dapat menjadi kampus tujuan utama bagi para Dosen berkualitas untuk mengabdi. POS (Perceived Organizational Support) digunakan untuk mengukur kondisi para Dosen, yang merasa bahwa institusi dimana mereka bernaung dapat menghargai kontribusi mereka. Sementara OCB (Organizational Citizenship Behaviour) pada penelitian ini merupakan kondisi dimana para Dosen bekerja sama dan saling membantu rekan Dosen lainnya untuk mencapai tujuan bersama di dalam proses perkuliahan. Penelitian ini bersifat analisis deskriptif dengan menggunakan pendekatan kuantitatif untuk mendapatkan pemahaman, gambaran serta penjelasan yang dapat dianalisis secara akurat ke dalam bentuk angka sehingga dapat dianalisis dan diinterpretasikan terhadap komitmen organisasi. Data yang diperoleh dari survei menggunakan POS kemudian diolah menggunakan pendekatan framework Cobit 4.1. untuk menghasilkan Maturity Level. Hasil dari penelitian ini berupa nilai skala Maturity yang dapat digunakan sebagai rekomendasi kepada pihak manajemen institusi untuk mendukung peningkatan kualitas Dosen dalam mencapai tujuan organisasi.
\end{abstract}

Kata kunci: Audit, Organizational Citizenship Behaviour, Perceived Organizational Support.

\begin{abstract}
The increased demand of labour in Information Technology, is in line with the rapidly expanding business world involving IT itself. Followed by the emergence of IT campuses, lead competition to viable upon the demand for qualified graduates, enabling them to compete and contribute their utmost to achieve goals that expected by the marketplace. This cannot be detached from the availability of Lecturers who meet the standards and qualifications. STMIK STIKOM Bali as one of the leading IT campuses in Bali and Nusa Tenggara is foreseeable to be option for qualified lecturers leadup. Perceived Organizational Support (POS) is used to measure the lecturers' behavior toward their feeling on the institutions' appreciation of their contributions. While the Organizational Citizenship Behaviour $(O C B)$ in this study is a condition where the Lecturers work together and help each other Lecturers, both permanent lecturers and home-based lecturers, to achieve common goals in the lecture process. OCB shows an important role to the effectiveness of the organization. This research is a descriptive analysis by using quantitative approach to get comprehension, description, and explanation, which can be analyzed accurately, and can interpret result of analysis from $O C B$ to organizational commitment at STMIK STIKOM Bali Lecturer. The obtained data from the conducted survey using POS is then processed using Cobit 4.1 framework approach to generate Maturity Level, both actual and expectation targets. The result of this research is Maturity Models scale value that can also be used as recommendation to institutional management to support the improvement of Lecturer quality in achieving organizational goals.
\end{abstract}

Keywords: Audit, Organizational Citizenship Behaviour, Perceived Organizational Support. 


\section{Pendahuluan}

Sejalan dengan perkembangan dunia usaha yang semakin pesat, yang melibatkan Teknologi Informasi (TI), permintaan tenaga kerja TI semakin banyak. Hal ini diikuti dengan kemunculan kampuskampus TI baru yang menyebabkan persaingan antar kampus berlangsung semakin kompetitif dikarenakan adanya tuntutan akan lulusan yang berkualitas, agar mampu bersaing dan memberikan kontribusi berupa hasil kerja yang maksimal sesuai yang diharapkan oleh pasar.

Rilis Peringkat Perguruan Tinggi pada bulan Februari tahun 2016 menyatakan bahwa Sekolah Tinggi Manajemen Informatika dan Teknik Komputer (STMIK) STIKOM Bali meraih peringkat 3 nasional dan peringkat 1 Bali Nusra. STMIK STIKOM Bali berada di urutan ketiga setelah STMIK Jakarta STI\&K dan STMIK Amikom Yogyakarta. Hal itu tertuang dalam SK Menristek dan Dikti RI Nomor: 492.a/M/Kp/VIII/2015 tentang Klasifikasi dan Pemeringkatan Perguruan Tinggi di Indonesia Tahun 2015 tertanggal 14 Agustus 2015, setelah mengevaluasi 3.320 PT di seluruh Indonesia.

Sebagai salah satu perguruan tinggi swasta yang menjadi tujuan para lulusan sekolah menengah, STMIK STIKOM Bali diharapkan mampu menghasilkan lulusan yang mampu bersaing dan memberikan kontribusi berupa hasil kerja yang maksimal. Hal ini tidak dapat dilepaskan dari ketersediaan Dosen yang memenuhi standar dan kualifikasi STMIK STIKOM Bali.

Peneliti menganggap faktor ini perlu diteliti, apakah STMIK STIKOM Bali merupakan kampus tujuan utama bagi para Dosen berkualitas untuk mengabdi, sehingga menjadi referensi dan memiliki nilai lebih sebagai tujuan utama para calon mahasiswa untuk menuntut ilmu, dengan menggunakan POS (Perceived Organizational Support) dan komitmen organisasi terhadap OCB (Organizational Citizenship Behaviour) dari para Dosen, baik tetap maupun home-based. Data yang diperoleh dari survei menggunakan POS kemudian diolah menggunakan pendekatan Framework Cobit 4.1. untuk menghasilkan Maturity Level. Hasil dari penelitian ini berupa nilai skala Maturity yang dapat digunakan sebagai rekomendasi kepada pihak manajemen institusi untuk mendukung peningkatan kualitas Dosen dalam mencapai tujuan organisasi.

\section{Tinjauan Pustaka}

\subsection{Perceived Organizational Support}

Perceived Organizational Support (POS) merupakan persepsi karyawan terhadap bagaimana organisasi menghargai kontribusi mereka dan peduli terhadap kesejahteraan mereka (Eisenberger) dalam Paille, Bourdeau, \& Galois (2010). Hal ini menunjukkan bahwa komitmen dari organisasi kepada karyawannya dapat sangat bermanfaat. POS menunjukkan perlakuan yang baik dari organisasi menciptakan kewajiban umum, berdasarkan norma timbal balik dari karyawan untuk peduli terhadap organisasi mereka dan memperlakukan organisasi mereka dengan baik sebagai pengembaliannya (Eisenberger et al.) dikutip oleh Ristig (2009). Kewajiban karyawan akan dibalaskan melalui perilaku terkait pekerjaan yang akan mendukung berbagai tujuan dari organisasi (Eisenberger et al.) dikutip oleh Ristig (2009).

Menurut Robbins (2008, p103) dukungan organisasi yang dirasakan atau Perceived Organizational Support adalah tingkat dimana karyawan yakin organisasi menghargai kontribusi mereka dan peduli dengan kesejahteraan mereka. POS dapat juga dipandang sebagai komitmen organisasi pada karyawan. Penghargaan yang diberikan oleh organisasi dapat dianggap memberikan keuntungan bagi karyawan, seperti adanya perasaan diterima dan diakui, memperoleh gaji dan promosi, mendapatkan berbagai akses informasi, serta beberapa bentuk bantuan lain yang dibutuhkan karyawan untuk dapat menjalankan pekerjaannya secara efektif.

Terdapatnya norma timbal balik ini menyebabkan karyawan dan organisasi harus saling memperhatikan beberapa tujuan yang ada dalam hubungan kerja tersebut (Rhoades dan Eisenberger dalam Fardina 2009).

Berdasarkan berbagai definisi tersebut, definisi Perceived Organizational Support dari Rhoades dan Eisenberger dalam Fatdina (2009) yang menjadi acuan penulis untuk melakukan penelitian kali ini.

\subsection{Organizational Citizenship Behaviour}

Istilah Perilaku Organizational Citizenship Behavior didefinisikan oleh Organ dalam Fatdina (2009) sebagai perilaku individual yang dengan kebebasan untuk menentukan atau memilih, tidak secara langsung atau eksplisit diakui oleh sistem reward formal, dan dalam keseluruhannya memajukan fungsi efektif organisasi.

Menurut Robbins (2008, p31) Organizational Citizenship Behavior adalah perilaku pilihan yang tidak menjadi bagian dari kewajiban kerja formal seorang karyawan namun mendukung berfungsinya organisasi tersebut secara efektif. Menurut Lovell, yang dikutip oleh Mohammad et al (2010) 
Organizational Citizenship Behavior adalah perilaku yang melampaui job description formal, persyaratan minimal yang diharapkan oleh organisasi dan mempromosikan kesejahteraan rekan kerja, kerja kelompok, atau organisasi.

Berdasarkan beberapa pendapat di atas, definisi Organization Citizenship Behavior menurut Robbins dan Judge (2008, p31) yang dipakai penulis untuk melakukan penelitian kali ini. Contoh nyata perilaku Organization Citizenship Behavior dalam kehidupan sehari-hari misalnya salah satu karyawan telah menyelesaikan tugasnya, dan tidak ada lagi tugas yang ia kerjakan, lalu ia putuskan untuk menolong mengerjakan tugas karyawan lain dengan tujuan agar tugas yang dikerjakan dapat dengan cepat terselesaikan.

\subsection{CobiT® 4.1}

CobiT (Control Objectives for Information and related Technology) menyediakan solusi untuk tata kelola teknologi informasi melalui domain, proses, tujuan, kegiatan, model kematangan dan struktur yang logis dan teratur. Kerangka ini dapat membantu optimalisasi investasi yang berkaitan dengan teknologi informasi, menjamin penyampaian layanan dan memberikan alat ukur/standar yang efektif untuk kepentingan manajemen. CobiT disusun oleh Information Systems Audit and Control Foundation (ISACA®) pada tahun 1996. Kemudian edisi kedua dari COBIT diterbitkan pada tahun 1998. Pada tahun 2000 dirilis COBIT 3.0 dan COBIT 4.0 pada tahun 2005. Kemudian COBIT 4.1 dirilis pada tahun 2007 dan saat ini COBIT yang terakhir dirilis adalah COBIT 5.0 yang dirilis pada Tahun 2012.

COBIT merupakan kombinasi dari prinsip-prinsip yang telah ditanamkan yang dilengkapi dengan balance scorecard dan dapat digunakan sebagai acuan model (seperti COSO) dan disejajarkan dengan standar industri, seperti ITIL, CMM, BS779, ISO 9000.

Terdapat beberapa acuan standar pengelolaan TI, diantaranya COBIT, COSO, ITIL, ISO dan lainnya. COBIT merupakan standar yang dinilai paling lengkap dan menyeluruh sebagai framework IT audit karena dikembangkan secara berkelanjutan oleh lembaga swadaya profesional auditor yang tersebar di hampir seluruh negara.

Dalam Penelitian ini, evaluasi dilakukan menggunakan Cobit 4.1. karena COBIT merupakan sebuah model framework tata kelola yang representatif dan menyeluruh, yang mencakup masalah perencanaan, implementasi, operasional dan pengawasan terhadap seluruh proses TI.

COBIT dapat membantu auditor, manajemen, dan pengguna untuk menjembatani pemisah (gap) antara risiko bisnis, kebutuhan pengendalian, dan permasalahan-permasalahan teknis. Maturity model untuk pengendalian dalam proses IT berisi tentang pengembangan Metode penilaian, sehingga organisasi dapat memberi penilaian sendiri dari non-existent sampai optimized (dari 0-5).

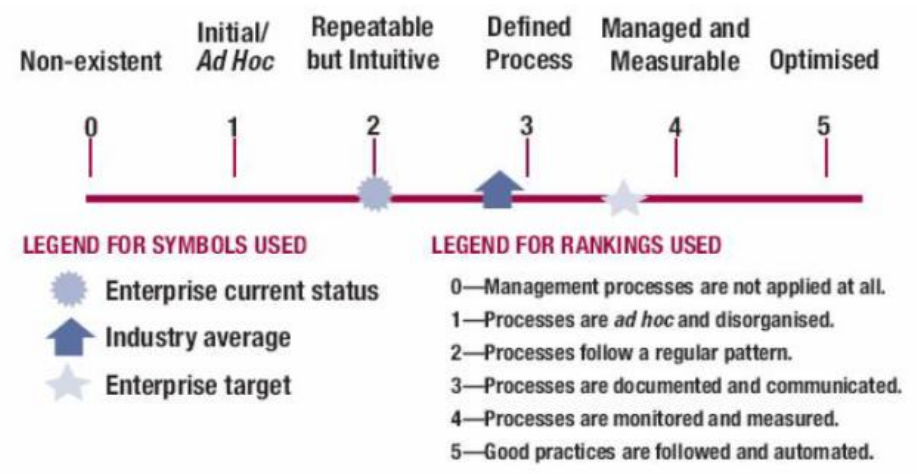

Gambar 1. Capability maturity model.

Berikut penjabaran dari level maturity models tersebut [6].

1. 0 - Non existent

Merupakan level maturity terendah, yang merupakan suatu kondisi dimana organisasi merasa tidak membutuhkan adanya mekanisme proses tata kelola TI yang baku, sehingga sama sekali tidak terdapat pengawasan terhadap tata kelola TI yang dilakukan oleh organisasi.

2. 1 - Initial

Terdapat beberapa inisiatif mekanisme perencanaan dan pengawasan sejumlah tata kelola TI yang dilakukan, namun tidak ada penilaian yang standar. 
3. 2 - Repeatable

Kondisi dimana organisasi telah memiliki kebiasaan yang terpola untuk merencanakan dan mengelola tata kelola TI dan dilakukan secara berulang-ulang secara reaktif, namun belum melibatkan prosedur dan dokumen formal.

4. 3 - Defined

Pada tahapan ini organisasi telah memiliki mekanisme dan prosedur yang jelas mengenai tata cara dan manajemen tata kelola TI, dan telah terkomunikasikan dan tersosialisasikan dengan baik di seluruh jajaran manajemen.

5. 4-Managed

Merupakan kondisi dimana manajemen organisasi telah menerapkan sejumlah indikator pengukuran kinerja kuantitatif untuk memonitor efektivitas pelaksanaan manajemen tata kelola TI.

6. 5 -Optimised

Level tertinggi ini diberikan kepada organisasi yang telah berhasil menerapkan prinsipprinsip tata kelola TI secara utuh dan mengacu pada best practise.

\section{Metode Penelitian}

Metode penelitian yang dilakukan terdiri dari 4 tahapan. Tahapan pertama adalah melakukan studi literatur mengenai data dosen STMIK STIKOM Bali dan kerangka COBIT yang akan digunakan. Hasil dari studi literatur akan menjadi dasar dalam melakukan analisis. Tahapan kedua adalah menyiapkan tabel pernyataan POS, OCB, dan AOC yang akan digunakan di dalam survei. Tahapan ketiga adalah melakukan pengumpulan data melalui survei. Pada tahapan ini dilakukan pembuatan kuesioner sebagai alat untuk pengukuran data. Kuesioner disebarkan pada para dosen, baik dosen tetap maupun dosen home-based yang terdaftar di STMIK STIKOM Bali. Tahapan yang terakhir adalah pengambilan kesimpulan terhadap hasil dari analisis data.

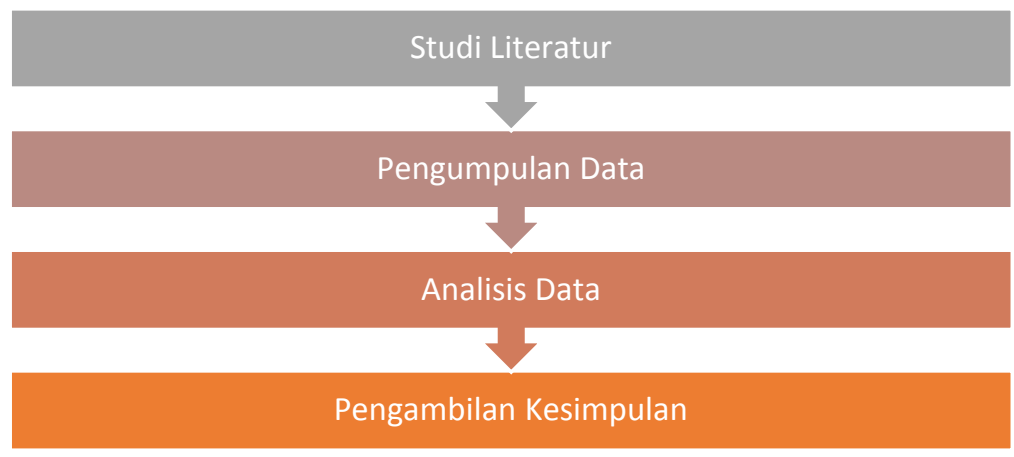

Gambar 2. Metode penelitian.

\subsection{Pengumpulan Data}

Data yang digunakan dalam penelitian ini adalah data primer dan data sekunder. Data primer adalah data yang dikumpulkan langsung oleh peneliti atau yang memerlukan data di lapangan. Data primer didapatkan dari individu atau perseorangan. Data primer pada penelitian ini adalah hasil jawaban kuesioner yang disebarkan pada para dosen, baik dosen tetap maupun dosen home-based yang terdaftar di STMIK STIKOM Bali. Sedangkan data sekunder adalah data yang dikumpulkan oleh peneliti atau yang memerlukan melalui sumber-sumber yang telah ada. Data ini digunakan untuk mendukung data primer yang sudah didapatkan. Data sekunder pada penelitian ini adalah literatur, buku dan bahan pustaka lainnya.

\subsection{Analisis Data}

Kuesioner yang disebar untuk pengambilan data terdiri dari bagian berisi identitas responden, bagian petunjuk pengisian, dan bagian terakhir berisi sejumlah pernyataan yang terstruktur mengenai konstruk-konstruk penelitian meliputi POS, OCB dan AOC.

POS, OCB, dan AOC menggunakan skala 5-poin; mulai dari 1 untuk STS (Sangat Tidak Setuju) hingga 5 untuk SS (Sangat Setuju) terhadap tanggapan pada masing-masing pernyataan.

Jumlah pernyataan adalah 16 yang mewakili 6 untuk pernyataan POS, 2 untuk pernyataan OCB dan 8 untuk pernyataan AOC. 
Bobot penilaian pada masing-masing variabel adalah sebagai berikut:

- SS (Sangat Setuju) mempunyai nilai 5.

- $\quad$ S (Setuju) mempunyai nilai 4.

- CS (Cukup Setuju) mempunyai nilai 3.

- TS (Tidak Setuju) mempunyai nilai 2.

- STS (Sangat Tidak Setuju) mempunyai nilai 1.

Tabel 1 menunjukkan keseluruhan 16 pernyataan. Tabel 2, 3 dan 4 menunjukkan masing-masing pernyataan yang termasuk dalam sub-skala OCB, POS dan Komitmen Organisasi masing-masing untuk 6, 2 dan 8 pernyataan.

Tabel 1. Pernyataan kuesioner.

\begin{tabular}{|c|c|c|}
\hline No. & Pernyataan & Fokus \\
\hline 1 & $\begin{array}{l}\text { Secara keseluruhan, saya puas dengan STMIK STIKOM Bali sebagai tempat yang } \\
\text { tepat untuk bekerja. }\end{array}$ & Keterlibatan Dosen \\
\hline 2 & Saya tidak pernah berpikir untuk mencari pekerjaan baru di institusi lain. & \\
\hline 3 & $\begin{array}{l}\text { Saya memiliki informasi dan komunikasi yang saya butuhkan untuk melakukan } \\
\text { pekerjaan saya secara efektif. }\end{array}$ & Komunikasi \\
\hline 4 & Institusi ini memberi saya kesempatan untuk membantu masyarakat setempat. & Memperlakukan Sesama \\
\hline 5 & $\begin{array}{l}\text { Saya merasa bahwa saya diperlakukan seperti yang saya harapkan untuk } \\
\text { diperlakukan. }\end{array}$ & \\
\hline 6 & $\begin{array}{l}\text { Saya memiliki sumber daya (mis., persediaan, peralatan, teknologi, dll.) yang saya } \\
\text { perlukan untuk melakukan pekerjaan saya secara efektif. }\end{array}$ & Pemberdayaan \\
\hline 7 & $\begin{array}{l}\text { Orang-orang yang bekerja dengan saya bekerja sama untuk menyelesaikan } \\
\text { pekerjaan. }\end{array}$ & \\
\hline 8 & $\begin{array}{l}\text { Saya merasa ada masa depan yang menjanjikan bagi saya di STMIK STIKOM } \\
\text { Bali. }\end{array}$ & Visi \\
\hline 9 & Saya percaya STMIK STIKOM Bali memiliki masa depan yang luar biasa. & \\
\hline 10 & $\begin{array}{l}\text { Saya diberi kesempatan nyata untuk meningkatkan kemampuan saya di institusi } \\
\text { ini. }\end{array}$ & Pengembangan \\
\hline 11 & $\begin{array}{l}\text { Saya memiliki kesempatan, yang sama dengan rekan lain, untuk mendapat } \\
\text { kemajuan di institusi ini. }\end{array}$ & \\
\hline 12 & $\begin{array}{l}\text { Apabila berada di posisi sebagai mahasiswa, saya akan sangat puas dengan } \\
\text { kualitas produk dan layanan yang saya terima. }\end{array}$ & Advokasi \\
\hline 13 & $\begin{array}{l}\text { Upaya inovasi dalam institusi ini telah membuat kemajuan dalam keseluruhan } \\
\text { pengetahuan mahasiswa. }\end{array}$ & Inovasi \\
\hline 14 & $\begin{array}{l}\text { STMIK STIKOM Bali berkomitmen untuk menyediakan produk dan layanan } \\
\text { berkualitas tinggi untuk mahasiswa. }\end{array}$ & Efektivitas Kepemimpinan \\
\hline 15 & Sebagai Dosen, saya merasa dihargai di STMIK STIKOM Bali. & Penghargaan \\
\hline 16 & $\begin{array}{l}\text { Tingkat upah saya sangat kompetitif dibandingkan dengan institusi lain di daerah } \\
\text { ini. }\end{array}$ & Kompensasi \\
\hline
\end{tabular}

Tabel 2. Daftar pernyataan perceived organizational support.

\begin{tabular}{clc}
\hline No. & \multicolumn{1}{c}{$\begin{array}{c}\text { Pernyataan } \\
\text { Perceived Organizational Support }\left(\mathbf{X}_{\mathbf{1}}\right)\end{array}$} & Fokus \\
\hline 3 & $\begin{array}{l}\text { Saya memiliki informasi dan komunikasi yang saya butuhkan untuk melakukan } \\
\text { pekerjaan saya secara efektif. }\end{array}$ & Komunikasi \\
\hline 4 & Institusi ini memberi saya kesempatan untuk membantu masyarakat setempat. & Memperlakukan Sesama \\
\hline 5 & $\begin{array}{l}\text { Saya merasa bahwa saya diperlakukan seperti yang saya harapkan untuk } \\
\text { diperlakukan. }\end{array}$ & Pemberdayaan \\
\hline 6 & $\begin{array}{l}\text { Saya memiliki sumber daya (mis., persediaan, peralatan, teknologi, dll.) yang saya } \\
\text { perlukan untuk melakukan pekerjaan saya secara efektif. }\end{array}$ & Pengembangan \\
\hline 10 & $\begin{array}{l}\text { Saya diberi kesempatan nyata untuk meningkatkan kemampuan saya di institusi } \\
\text { ini. }\end{array}$ & $\begin{array}{l}\text { Saya memiliki kesempatan, yang sama dengan rekan lain, untuk mendapat } \\
\text { kemajuan di institusi ini. }\end{array}$ \\
\hline 11
\end{tabular}

Sumber: Data Diolah, 2017

Tabel 3. Daftar pernyataan organizational citizenship behaviour.

\begin{tabular}{clc}
\hline No. & \multicolumn{1}{c}{ OCB $($ Organizational Citisenship Behaviour) $-\boldsymbol{Y}$} & Fokus \\
\hline 7 & $\begin{array}{l}\text { Orang-orang yang bekerja dengan saya bekerja sama untuk menyelesaikan } \\
\text { pekerjaan. }\end{array}$ & Pemberdayaan \\
\hline
\end{tabular}




\begin{tabular}{ccc}
\hline 15 & Sebagai Dosen, saya merasa dihargai di STMIK STIKOM Bali. & Penghargaan \\
\hline Sumber: Data Diolah, 2017 &
\end{tabular}

Tabel 4. Daftar pernyataan affective organizational commitment.

\begin{tabular}{clc}
\hline No. & \multicolumn{1}{c}{ Affective Organizational Commitment $\left(\mathbf{X}_{\mathbf{2}}\right)$} & \multicolumn{1}{c}{$\begin{array}{c}\text { Pernyataan } \\
\text { Fokus }\end{array}$} \\
\hline 1 & $\begin{array}{l}\text { Secara keseluruhan, saya puas dengan STMIK STIKOM Bali sebagai tempat yang } \\
\text { tepat untuk bekerja. }\end{array}$ & Keterlibatan Dosen \\
\hline 2 & Saya tidak pernah berpikir untuk mencari pekerjaan baru di institusi lain. & Visi \\
\hline 8 & $\begin{array}{l}\text { Saya merasa ada masa depan yang menjanjikan bagi saya di STMIK STIKOM } \\
\text { Bali. }\end{array}$ & Advokasi \\
\hline 9 & Saya percaya STMIK STIKOM Bali memiliki masa depan yang luar biasa. & Inovasi \\
\hline 12 & $\begin{array}{l}\text { Apabila berada di posisi sebagai mahasiswa, saya akan sangat puas dengan } \\
\text { kualitas produk dan layanan yang saya terima. }\end{array}$ & $\begin{array}{l}\text { Efektivitas } \\
\text { Kepemimpinan }\end{array}$ \\
\hline 14 & $\begin{array}{l}\text { Upaya inovasi dalam institusi ini telah membuat kemajuan dalam keseluruhan } \\
\text { pengetahuan mahasiswa. } \\
\text { berkualitas tinggi untuk mahasiswa. }\end{array}$ & Kompensasi \\
\hline 16 & $\begin{array}{l}\text { Tingkat upah saya sangat kompetitif dibandingkan dengan institusi lain di daerah } \\
\text { ini. }\end{array}$ & \\
\hline Sumber: Data Diolah, 2017 &
\end{tabular}

\section{Hasil dan Pembahasan}

Hasil survei pra-research dilakukan terhadap 25 orang Dosen dari total kuesioner yang dikirimkan kepada 165 Dosen, baik Dosen Tetap maupun Dosen Home-Based di STMIK STIKOM Bali. Dari penyebaran kuesioner, karakteristik responden dijelaskan secara umum dapat dilihat dari jenis kelamin, masa kerja dan pendidikan terakhir dengan jumlah responden sebanyak 25 orang.

Tabel 5. Karakteristik responden.

\begin{tabular}{|c|c|c|c|c|c|}
\hline No. & Variabel & Klasifikasi & & $\begin{array}{l}\begin{array}{l}\text { Jumlah } \\
\text { (orang) }\end{array} \\
\end{array}$ & Persentase \\
\hline \multirow{3}{*}{1} & \multirow{3}{*}{ Jenis Kelamin } & Laki-laki & & 15 & 60 \\
\hline & & Perempuan & & 10 & 40 \\
\hline & & & Jumlah & 25 & 100 \\
\hline \multirow{5}{*}{2} & \multirow{5}{*}{ Masa Kerja } & $1-3$ & & 11 & 44 \\
\hline & & $3-5$ & & 5 & 20 \\
\hline & & $5-10$ & & 5 & 20 \\
\hline & & $>10$ & & 4 & 16 \\
\hline & & & Jumlah & 25 & 100 \\
\hline \multirow{6}{*}{3} & \multirow{6}{*}{ Pendidikan Terakhir } & Magister Informatika & & 11 & 44 \\
\hline & & Magister Teknik & & 5 & 20 \\
\hline & & Magister Manajemen & & 4 & 16 \\
\hline & & Magister Pendidikan & & 3 & 12 \\
\hline & & Magister Humaniora & & 2 & 8 \\
\hline & & & Jumlah & 25 & 100 \\
\hline
\end{tabular}

Sumber: Data Diolah, 2017

Pada Tabel 5 menunjukkan tiga karakteristik dari responden yang terdiri dari jenis kelamin, masa kerja dan pendidikan terakhir. Responden pada penelitian menunjukkan bahwa jenis kelamin lakilaki berjumlah 15 orang atau sebesar 60 persen. Sedangkan jenis kelamin perempuan berjumlah 10 orang atau sebesar 40 persen. Masa kerja dalam responden penelitian ini mulai dari 1-3 tahun sebanyak 11 orang atau sebesar 44 persen, kemudian masa kerja 3-5 tahun sebanyak 5 orang atau sebesar 20 persen, dilanjutkan dengan masa kerja 5-10 tahun sebanyak 5 orang atau sebesar 20 persen dan masa kerja di atas 10 tahun sebanyak 4 orang atau sebesar 16 persen. Pendidikan terakhir pada responden Penelitian ini sebagian besar adalah Magister Informatika sebanyak 11 orang atau sebesar 44 persen, diikuti oleh Magister Teknik sebanyak 5 orang atau sebesar 20 persen, Magister Manajemen sebanyak 4 orang atau 16 persen, Magister Pendidikan sebanyak 3 orang atau 12 persen dan magister Humaniora sebanyak 2 orang atau 8 persen.

Pada Tabel 6 dan Tabel 7 menunjukkan respons dari responden yang digunakan sebagai indikator. Untuk pernyataan 2 (P2) "Saya tidak pernah berpikir untuk mencari pekerjaan baru di institusi 
lain.” 1 orang atau 4\% menyatakan Sangat Tidak Setuju (STS) dan 4 orang atau 16\% menyatakan Tidak Setuju (TS). Untuk pernyataan 3 (P3) "Saya memiliki informasi dan komunikasi yang saya butuhkan untuk melakukan pekerjaan saya secara efektif." 1 orang atau 4\% menyatakan Tidak Setuju (STS). Untuk pernyataan 5 (P5) "Saya merasa bahwa saya diperlakukan seperti yang saya harapkan untuk diperlakukan." 1 orang atau 4\% menyatakan Tidak Setuju (STS). Untuk pernyataan 8 (P8) "Saya merasa ada masa depan yang menjanjikan bagi saya di STMIK STIKOM Bali." 1 orang atau 4\% menyatakan Tidak Setuju (STS). Untuk pernyataan 9 (P9) "Saya percaya STMIK STIKOM Bali memiliki masa depan yang luar biasa." 1 orang atau 4\% menyatakan Tidak Setuju (STS). Untuk pernyataan 16 (P16) "Tingkat upah saya sangat kompetitif dibandingkan dengan institusi lain di daerah ini." 1 orang atau 4\% menyatakan Tidak Setuju (STS).

Terdapat respons Cukup Setuju (CS) pada semua pernyataan, yang menunjukkan bahwa responden berada diposisi antara Setuju (S) dan Tidak Setuju (TS).

Tabel 6. Hasil respons responden.

\begin{tabular}{lrrrrrrrrrrrrrrrr}
\hline Respons & P1 & P2 & P3 & P4 & P5 & P6 & P7 & P8 & P9 & P10 & P11 & P12 & P13 & P14 & P15 & P16 \\
\hline Sangat Setuju & 9 & 6 & 4 & 11 & 3 & 4 & 7 & 6 & 12 & 10 & 6 & 3 & 1 & 4 & 3 & 2 \\
Setuju & 13 & 7 & 18 & 12 & 17 & 18 & 15 & 12 & 8 & 12 & 15 & 19 & 20 & 18 & 17 & 12 \\
Cukup Setuju & 3 & 7 & 2 & 2 & 4 & 3 & 3 & 6 & 4 & 3 & 4 & 3 & 4 & 3 & 5 & 10 \\
Tidak Setuju & 0 & 4 & 1 & 0 & 1 & 0 & 0 & 1 & 1 & 0 & 0 & 0 & 0 & 0 & 0 & 1 \\
Sangat Tidak Setuju & 0 & 1 & 0 & 0 & 0 & 0 & 0 & 0 & 0 & 0 & 0 & 0 & 0 & 0 & 0 & 0 \\
\hline Jumlah & $\mathbf{2 5}$ & $\mathbf{2 5}$ & $\mathbf{2 5}$ & $\mathbf{2 5}$ & $\mathbf{2 5}$ & $\mathbf{2 5}$ & $\mathbf{2 5}$ & $\mathbf{2 5}$ & $\mathbf{2 5}$ & $\mathbf{2 5}$ & $\mathbf{2 5}$ & $\mathbf{2 5}$ & $\mathbf{2 5}$ & $\mathbf{2 5}$ & $\mathbf{2 5}$ & $\mathbf{2 5}$ \\
\hline
\end{tabular}

Tabel 7. Hasil respons responden dalam persentase.

\begin{tabular}{|c|c|c|c|c|c|c|c|c|c|c|c|c|c|c|c|c|}
\hline Respons & P1 & $\mathbf{P 2}$ & P3 & P4 & P5 & P6 & P7 & P8 & P9 & P10 & P11 & P12 & P13 & P14 & P15 & P16 \\
\hline Sangat Setuju & 36 & 24 & 16 & 44 & 12 & 16 & 28 & 24 & 48 & 40 & 24 & 12 & 4 & 16 & 12 & 8 \\
\hline Setuju & 52 & 28 & 72 & 48 & 68 & 72 & 60 & 48 & 32 & 48 & 60 & 76 & 80 & 72 & 68 & 48 \\
\hline Cukup Setuju & 12 & 28 & 8 & 8 & 16 & 12 & 12 & 24 & 16 & 12 & 16 & 12 & 16 & 12 & 20 & 40 \\
\hline $\begin{array}{l}\text { Tidak Setuju } \\
\text { Sangat Tidak }\end{array}$ & 0 & 16 & 4 & 0 & 4 & 0 & 0 & 4 & 4 & 0 & 0 & 0 & 0 & 0 & 0 & 4 \\
\hline Setuju & 0 & 4 & 0 & 0 & 0 & 0 & 0 & 0 & 0 & 0 & 0 & 0 & 0 & 0 & 0 & 0 \\
\hline Jumlah & 100 & 100 & 100 & 100 & 100 & 100 & 100 & 100 & 100 & 100 & 100 & 100 & 100 & 100 & 100 & 100 \\
\hline
\end{tabular}

Sumber: Data Diolah, 2017

Perceived Organizational Support (POS) adalah persepsi karyawan mengenai sejauh mana organisasi dapat memberi dukungan pada karyawan. pada penelitian ini merupakan suatu kondisi karyawan, dalam hal ini Dosen, yang merasa bahwa organisasinya (STMIK STIKOM Bali) dapat menghargai kontribusi mereka. POS pada Dosen dapat muncul melalui kebijakan dan praktik organisasi yang adil, baik terhadap dosen tetap maupun dosen home-based, dan melalui penghargaan performa kerja dan kondisi kerja yang kondusif.

Organizational Citizenship Behaviour (OCB) merupakan perilaku positif bagi perusahaan yang sifatnya non-formal karena karyawan menolong dengan sukarela di luar dari pekerjaan formal yang telah diberikan oleh organisasi tanpa adanya penghargaan. OCB pada penelitian ini merupakan suatu kondisi karyawan, dalam hal ini Dosen, yang saling membantu Dosen lainnya, baik dosen tetap maupun dosen home-based, mengajukan diri untuk melakukan pekerjaan ekstra, melindungi property kampus STMIK STIKOM Bali, menghindari konflik yang tidak perlu, menghargai support dan peraturan yang berlaku, memberikan saran-saran yang membangun, serta rasa toleransi terhadap gangguan terkait proses perkuliahan. OCB menunjukkan peranan penting terhadap efektivitas organisasi. Sebuah organisasi dikatakan efektif bila keinginan keluar karyawan rendah dan kepuasan kerjanya tinggi. Jika karyawan memiliki tingkat OCB yang tinggi maka akan menurunkan keinginan keluar, sebaliknya jika OCB rendah maka akan meningkatkan keinginan keluar.

Pada penelitian ini, penerapan Cobit pada perhitungan kuesioner dilakukan untuk proses-proses di domain Delivery and Support (DS) dan Monitoring and Evaluation (ME). 
Tabel 8. Rekap hasil perhitungan nilai maturity level.

\begin{tabular}{clc}
\hline No. & \multicolumn{1}{c}{ Pernyataan } & Proses \\
\hline \multirow{2}{*}{3} & Perceived Organizational Support & \\
\hline \multirow{2}{*}{6} & Saya memiliki informasi dan komunikasi yang saya butuhkan untuk & DS1, \\
& melakukan pekerjaan saya secara efektif. & DS8 \\
\hline \multirow{2}{*}{6} & Saya memiliki sumber daya (mis., persediaan, peralatan, teknologi, dll.) & DS3, \\
& yang saya perlukan untuk melakukan pekerjaan saya secara efektif. & DS4 \\
\hline \multirow{2}{*}{13} & Affective Organizational Commitment & \\
\hline \multirow{2}{*}{14} & Upaya inovasi dalam institusi ini telah membuat kemajuan dalam & DS10, \\
& keseluruhan pengetahuan mahasiswa. & DS12 \\
\hline & STMIK STIKOM Bali berkomitmen untuk menyediakan produk dan & ME1, \\
& layanan berkualitas tinggi untuk mahasiswa. & ME2 \\
\hline
\end{tabular}

Tabel 9. Rekap hasil perhitungan nilai maturity level.

\begin{tabular}{clll}
\hline No. & & \multicolumn{1}{c}{ CONTROL OBJECTIVES } & $\begin{array}{c}\text { Maturity } \\
\text { Level }\end{array}$ \\
\hline 1 & DS1 & Define and Manage Service Levels & 2.791 \\
\hline 2 & DS3 & Manage Performance and Capacity & 2.747 \\
\hline 3 & DS4 & Ensure Continuous Service & 2.814 \\
\hline 4 & DS8 & Manage Service Desk and Incidents & 2.797 \\
\hline 5 & DS10 & Manage Problems & 2.565 \\
\hline 6 & DS12 & Manage the Physical Environment & 2.628 \\
\hline 7 & DS13 & Manage Operations & 2.861 \\
\hline 8 & ME1 & Monitor and Evaluate IT performance & 2.615 \\
\hline 9 & ME2 & Monitor and Evaluate Internal Control & 2.465 \\
\hline
\end{tabular}

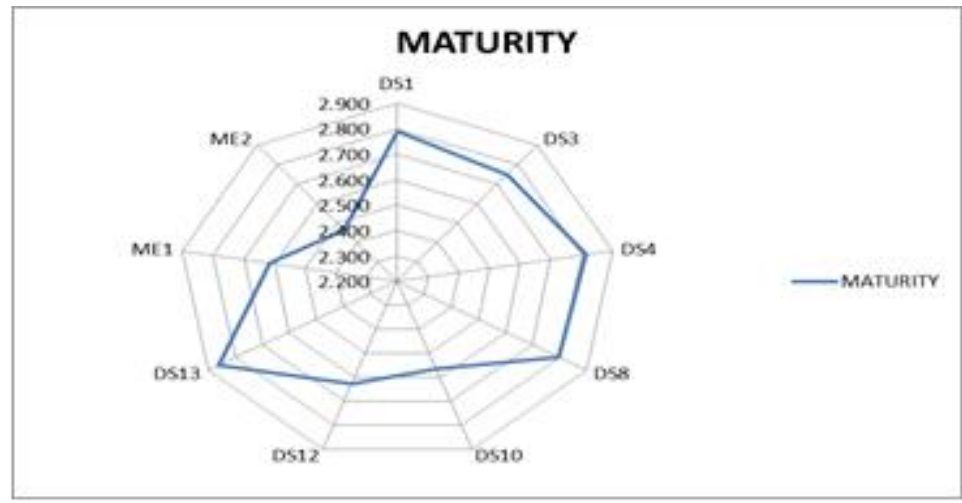

Gambar 3. Radar chart hasil perhitungan nilai maturity level.

\section{Simpulan}

Berdasarkan hasil analisis penelitian dan hasil pembahasan, maka simpulan dari penelitian ini adalah sebagai berikut:

Perceived Organizational Support (POS) dan Organizational Citizenship Behaviour (OCB) berpengaruh positif terhadap Affective Organizational Commitment (AOC). Walaupun demikian terdapat keragu-raguan yang dapat dilihat pada respons Cukup Setuju (CS) pada semua pernyataan, yang menunjukkan bahwa responden berada diposisi antara Setuju (S) dan Tidak Setuju (TS).

Hasil penelitian ini menunjukkan STMIK STIKOM Bali berada pada skala maturity level dibawah 3, menggunakan skala 4. Rekomendasi untuk manajemen organisasi, dalam hal ini STMIK STIKOM Bali, diantaranya untuk dapat meningkatkan sumber daya (mis., persediaan, peralatan, teknologi, dll.) agar para Dosen dapat melakukan pekerjaan mereka secara efektif yang berdampak pada performa kerja dan meningkatkan bobot nilai dari POS. Untuk lanjutan penelitian berikutnya, data yang ada dapat dikembangkan lagi dengan data yang lebih besar dan lebih bervariasi, termasuk dalam hal ini jumlah responden dan jenis pernyataan, sehingga menghasilkan data yang lebih akurat.

\section{Daftar Pustaka}


[1] Cobit 4.1. Executive Summary Framework. https://www.isaca.org/KnowledgeCenter/cobit/Documents/COBIT4.pdf

[2] Gunawan, H. \& Santosa, E. C. (2012). Politik Organisasi Dan Dampaknya Terhadap Komitmen Organisasi, Kepuasan Kerja, Kinerja Dan Organizational Citizenship Behavior (OCB). Jurnal Manajemen, Vol.12, No.1, November 2012.

[3] Ilies, R., Fulmer, I. S., Spitzmuller, M., \& Johnson, M. D. (2009). Personality and citizenship behavior: the mediating role of job satisfaction. Journal of Applied Psychology, 94(4), 945.

[4] Indrajit, R. E. (2013). Membaca Kerangka Cobit versi 4.x. E-Artikel Sistem dan Teknologi Informasi, Seri 999.

[5] Kurtessis, J. N., Eisenberger, R., Ford, M. T., Buffardi, L. C., Stewart, K. A., \& Adis, C. S. (2017). Perceived organizational support: A meta-analytic evaluation of organizational support theory. Journal of Management, 43(6), 1854-1884.

[6] Laksito, A. D., Kusrini, K., \& Luthfi, E. T. (2013). PENGUKURAN TINGKAT MODEL KEMATANGAN PROSES COBIT MENGGUNAKAN APLIKASI BERBASIS WEB (Studi Kasus di STMIK AMIKOM Yogyakarta). SEMNASTEKNOMEDIA ONLINE, 1(1), 26-1.

[7] Malik, M. E., Nawab, S., Naeem, B., \& Danish, R. Q. (2010). Job satisfaction and organizational commitment of university teachers in public sector of Pakistan. International Journal of Business and Management, 5(6), 17.

[8] Paillé, P., Bourdeau, L., \& Galois, I. (2010). Support, trust, satisfaction, intent to leave and citizenship at organizational level: A social exchange approach. International Journal of Organizational Analysis, 18(1), 41-58.

[9] Podsakoff, N. P., Whiting, S. W., Podsakoff, P. M., \& Blume, B. D. (2009). Individual-and organizational-level consequences of organizational citizenship behaviors: A meta-analysis.

[10] Robbins, S.P. and Judge, T.A. (2008). Organizational Behavior. Pearson Prentice Hall. 